\title{
Subsequent Development of Epithelial Ovarian Cancer After Ovarian Surgery for Benign Ovarian Tumor: A Population-Based Cohort Study
}

This article was published in the following Dove Press journal: Clinical Epidemiology

\author{
Chen-Yu Huang ${ }^{1,2}$ \\ Wen-Hsun Chang ${ }^{3,4}$ \\ Hsin-Yi Huang ${ }^{5}$ \\ Chao-Yu Guo (D) ${ }^{4,6}$ \\ Yiing-Jeng Chou (1D) 4,6 \\ Nicole Huang ${ }^{4,6}$ \\ Wen-Ling Lee $\mathbb{D}^{2,7,8}$ \\ Peng-Hui Wang (D) $1,2,9,10$ \\ 'Department of Obstetrics and \\ Gynecology, Taipei Veterans General \\ Hospital, Taipei, Taiwan; ${ }^{2}$ Institute of \\ Clinical Medicine, National Yang-Ming \\ University, Taipei, Taiwan; ${ }^{3}$ Department \\ of Nursing, Taipei Veterans General \\ Hospital, Taipei, Taiwan; ${ }^{4}$ Institute of \\ Hospital and Health Care Administration, \\ National Yang-Ming University, Taipei, \\ Taiwan; ${ }^{5}$ Biostatics Task Force, Taipei \\ Veterans General Hospital, Taipei, \\ Taiwan; ${ }^{6}$ Institute of Public Health, \\ National Yang-Ming University, Taipei, \\ Taiwan; ${ }^{7}$ Department of Medicine, \\ Cheng-Hsin General Hospital, Taipei, \\ Taiwan; ${ }^{8}$ Department of Nursing, \\ Oriental Institute of Technology, New \\ Taipei City, Taiwan; ${ }^{9}$ Female Cancer \\ Foundation, Taipei, Taiwan; ${ }^{10}$ Department \\ of Medical Research, China Medical \\ University Hospital, Taichung, Taiwan
}

Correspondence: Wen-Ling Lee Department of Medicine, Cheng-Hsin General Hospital, 45, Cheng-Hsin Street, Taipei, Taiwan

Email johnweiwang@gmail.com

Peng-Hui Wang

Department of Obstetrics and

Gynecology,Taipei Veterans General Hospital and National Yang-Ming

University School of Medicine, 20I,

Section 2, Shih-Pai Road, Taipei II2,

Taiwan

Fax +886-2-55702788

Email pongpongwang@gmail.com
Purpose: The goal of the current study is to determine the risk of subsequent development of epithelial ovarian cancer (EOC) in women after ovarian surgery for benign ovarian tumors.

Patients and Methods: We conducted the nationwide population-based historic cohort study using the National Health Insurance Research Database (NHIRD) of Taiwan. Eleven thousand six hundred twenty women who underwent ovarian surgery for ovarian benign diseases were analyzed. The collected data included age, types of ovarian surgery, medical history by Charlson comorbidity index (CCI), infertility (yes/no), pelvic inflammatory disease (PID) (yes/no), tubal ligation (yes/no), total/subtotal hysterectomy (TH/STH) (yes/no), and endometrioma (yes/no). We used the Kaplan-Meier method and the Log-rank test to evaluate the risk factors. Cox proportional hazard methods were used to evaluate risk factors for the subsequent development of EOC. Multivariate analysis using Cox stepwise forward regression was conducted for the covariate selected in univariate analysis. Hazard ratio (HR) and $95 \%$ confidence interval (CI) were calculated using the Wald test.

Results: Subsequent EOC incidence rate (IR, incidence per 10,000 person-years) of women after ovarian surgery for benign ovarian tumors was 2.98. Separating into four groups based on different age, IR of EOC was 1.57 ( $<30$ years), 4.71 (30-39 years), 3.59 (40-49 years) and 0.94 ( $\geq 50$ years), respectively. Univariate and multivariate analyses identified only high level of CCI ( $\geq 2$ or more) as an independent risk factor for subsequent development of EOC in women after ovarian surgery for benign ovarian tumors (HR 59.17, 95\% CI 7.50-466.80 in women with CCI level of 2 and HR 190.68, 95\% CI 24.33-2494.19, in women with CCI level $\geq 3$, respectively).

Conclusion: Our results, if confirmed, suggest that women with other comorbidities (CCI) should be well informed that they may have a higher risk of subsequent development of EOC when ovarian surgery is planned even though the final pathology showed a benign ovarian tumor.

Keywords: benign ovarian tumor, cohort study, epidemiology, epithelial ovarian cancer, ovarian surgery, risk

\section{Introduction}

Worldwide, epithelial ovarian cancer (EOC) is the most common cause of gynecological cancer death because of silent development and an advanced-stage at diagnosis. ${ }^{1-4}$ Treatment requires expert multidisciplinary care, including optimal definite cytoreductive surgery before/after (interval surgery) multiagent chemotherapy plus various kinds of targeted therapy, such as poly(ADP-ribose) polymerase 
inhibitors (PARP inhibitors), angiogenesis inhibitors (AIs), immune checkpoint inhibitors, and so on. ${ }^{5-11}$ Strides have been made to improve either progression-free survival or overall survival. $^{5-11}$ However, the outcome of EOC remains unsatisfactory with substantial debilitation to patients and the health care system. Given the nonspecific symptoms and aggressive natural history of EOC, and of most importance, the lack of established or effective screening test, the identification of risk factors, which have consistently been linked to EOC and additional risk-reductive strategies, are very important. ${ }^{12-24}$

Many factors are reported to have a correlation with the development of EOC. ${ }^{12-45}$ For example, endometriosis has long been shown to be risky of the development of EOC. ${ }^{25-34}$ Several studies have specifically addressed the higher risk of EOC in patients with a history or a diagnosis of endometriosis. Similar to the design from many population-based cohort studies, ${ }^{46-50}$ the majority of the study enrolled the relatively "healthy" women as the reference (standardized incidence rate [SIR]: standardized incidence per 10,000 person-years) for comparison, but the risk calculation is still varied greatly. ${ }^{35-45}$ In the real world, these "healthy" women might not receive any kinds of gynecological surgery in their life, such as tubal surgery, ovarian surgery, uterine surgery, including total/subtotal hysterectomy (TH/STH). However, some of these surgical procedures, such as bilateral salpingo-oophorectomy (BSO), bilateral oophorectomy (BO), TH and STH have long been shown to decrease the risk of the development EOC after surgery. ${ }^{12,17,20,23,39}$ In addition, only a few studies have assessed EOC risk related to prior ovarian surgery. ${ }^{51-56}$ Therefore, we conducted a large populationbased cohort study to evaluate the risk of subsequent development of EOC in women after ovarian surgery for benign ovarian tumors.

\section{Patients and Methods}

The Taiwanese National Health Insurance (NHI) program was founded in 1995, which enrolled more than $99 \%$ of the inhabitants living in Taiwan, and as of December 2010, it covered more than $99 \%$ of the population and contracted with almost all medical centers, hospitals, and clinics in Taiwan. ${ }^{46-50}$ This program also includes all inpatient and outpatient medical benefit claims. ${ }^{57-62}$ The National Health Research Institute (NHRI) cooperates with the Bureau of NHI to establish an NHI Research Database (NHIRD) in 2000 , and guards the privacy and confidentiality of all beneficiaries and provides health insurance data to researchers who have obtained ethical approval. ${ }^{25,40,41,57}$ The Longitudinal Health Insurance Database in 2000 (LHID 2000) contains all the original enrollment and claims data of 1 million beneficiaries, randomly sampled from the beneficiaries of the NHIRD during the period 1996 and 2000. The data of the sampled subjects in the LHID 2000 are representative of all beneficiaries, including age, sex, insurance cost, details of medical orders, procedures, and medical diagnoses with codes based on the International Classification of Diseases, Ninth Revision, Clinical Modifications (ICD9-CM). ${ }^{25,40,41,63}$ The identification of all patients in the LHID is encrypted and protects the privacy of patients. The NHRI provides access to the database for analysis.

This study was a retrospective population-based cohort study, containing a total of 322,534 women aged $\geq 20$ years of age. This study was based in part on data from the Taiwan National Health Insurance Research Database provided by the National Health Insurance Administration, Ministry of Health and Welfare and managed by National Health Research Institutes. According to the written operating procedures, Good Clinical Practice (GCP), and the applicable regulatory requirements, this study project was approved by the Institutional Review Board of Taipei Veterans General Hospital (IRB-TPEVGH No. 2019-07-039BC), and the board is organized under and operates according to International Conference on Harmonisation ( $\mathrm{ICH} / \mathrm{WHO}$ GCP) and the applicable laws and regulation. In addition, the study was carried out in accordance with the principles to the Declaration of Helsinki. The requirement of patient-informed consent was waived, since the identification of the study subjects in the database has been erased before we obtained the data.

Women treated with first ovarian surgery were included. However, women with a history of ovarian cancer before this enrollment and without any visit to obstetricians or gynecologists during the study period were excluded. To increase the identification validity of women with ovarian surgery in the administrative data set, only women with surgery-confirmed diagnosis of benign ovarian tumors during the period between January 1, 2000, and December 31, 2010 , were included. A total of 11,620 patients were enrolled in the current study (Figure 1).

EOC was initially detected using inpatients with a surgico-pathological diagnosis and validated using the major disease files (ICD-9-CM 183.0 from Registry for Catastrophic Illness Patients). The histological types were 


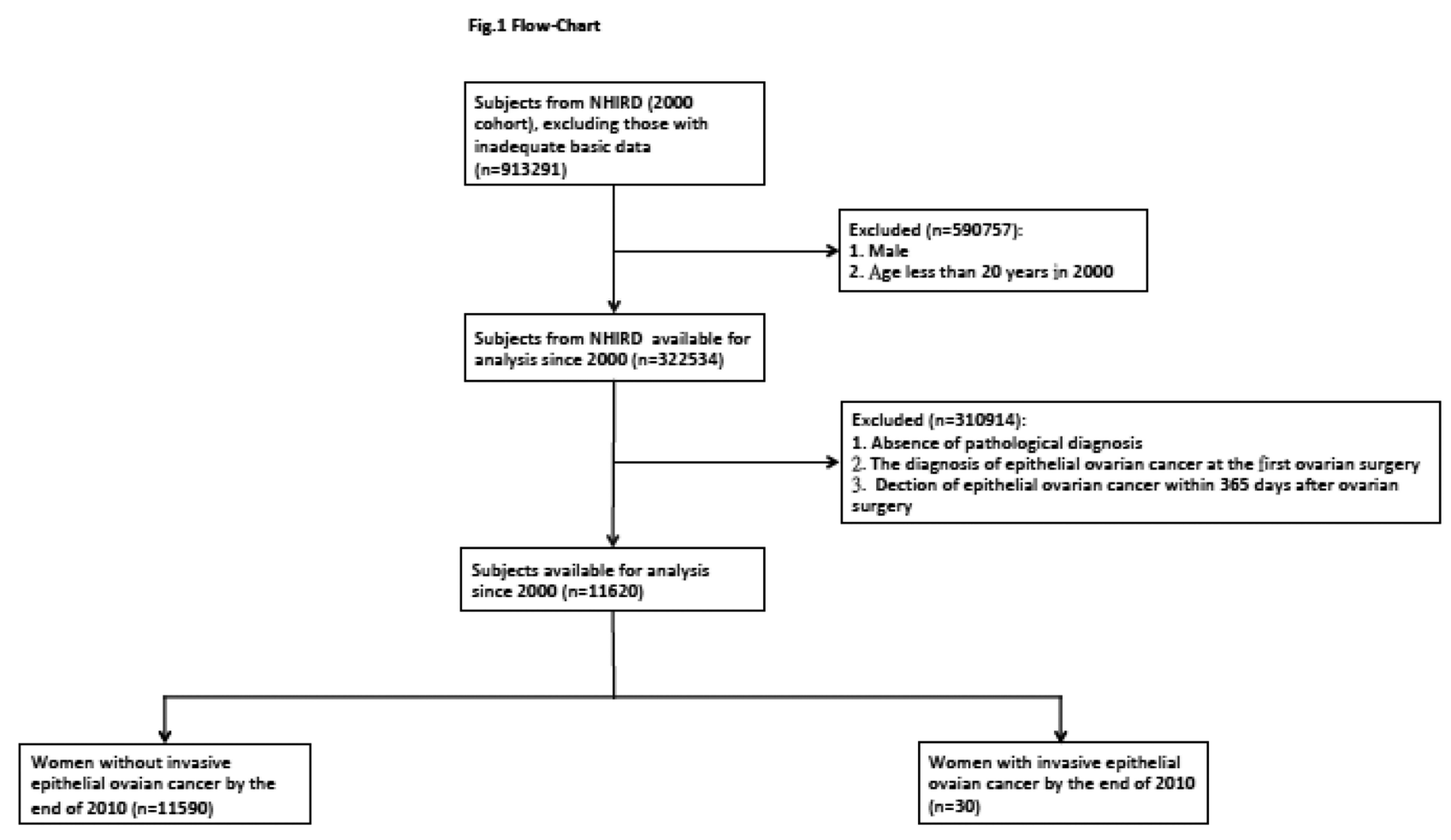

Figure I Flowchart of the current cohort study.

according to the World Health Organization Classification of Tumors. ${ }^{41,64,65}$ The included histological types were serous (8441/3, 8460/3, 8461/3), mucinous (8470/2, $8470 / 3,8471 / 3,8480 / 3,8482 / 3)$, endometrioid (8380/3, $8382 / 3$, 8383/3), clear cell $(8310 / 3,8313 / 3)$, malignant Brenner (9000/3), undifferentiated $(8020 / 3,8021 / 3)$, and carcinosarcoma $(8950 / 3,8980 / 3,8981 / 3)$. Since EOC can be diagnosed at the first ovarian surgery as well as synchronous benign ovarian tumors and uterine/cervical malignancy can be incidentally found, to clarify the subsequent risk of developing EOC in women after ovarian surgery, we excluded patients with the diagnosis of EOC at the first ovarian surgery and furthermore excluded women with a diagnosis of EOC within 365 days after her first ovarian surgery.

We used following ICD-9 CM codes (65.xx) to enrolled patients who underwent ovarian surgery, and for example, ICD-9 CM codes 65.01, 65.09, 65.31 or 65.39 were for unilateral oophorectomy (UO). The other detailed ICD-9 CM codes are shown in supplement 1 . In addition, to verify the role of tubal ligation, and total/subtotal hysterectomy on the subsequent development of EOC, these ICD-9 CM codes, including 68.3, 68.4, 68.5, 68.6, 68.7, 68.8 and 68.9 as well as 66.32 and 66.39 were used to identify these types of surgery.
To analyze the role of age in women after ovarian surgery for benign ovarian diseases on the subsequently developing EOC, we used 4 age groups (those $<30,30-39$, $40-39$, and $\geq 50$ years) to perform the age stratification analyses.

\section{Statistical Analysis}

Starting from the cohort index date, the study subjects were followed until the occurrence of hospitalization with EOC (ICD-9-CM 183.0) or death, whichever came first, or at the end of the study (December 31, 2010) if no EOC or death. The incidence rate of EOC was calculated every 10,000 person-years (IR, incidence per 10,000 person-years). Cases lost during the follow-up and those with subsequent development of EOC at the end of the follow-up period were considered censored observations. Survival curves were generated using the Kaplan-Meier method, and the differences between survival curves were calculated using the Log-rank test. Cox proportional hazard methods were used to evaluate prognostic factors for survival. Multivariate analysis using Cox stepwise forward regression was conducted for the covariate selected in univariate analysis. Hazard ratio (HR) and 95\% confidence interval (CI) were calculated using the Wald test. A P value $<0.05$ was considered to be statistically significant. All statistical analyses were 
conducted with SAS version 9.3 (SAS Institute, Cary, NC) and Stata Statistical Software, version 12.0 (Stata Corporation, College Station, TX).

\section{Results}

Among the total of 11,620 subjects, 30 subjects developed invasive EOC between 2001 and 2010 (Figures 1 and 2).

The subtypes of invasive EOC included serous type $(\mathrm{n}=11,36.7 \%)$, endometrioid type $(\mathrm{n}=7,23.3 \%)$, clear cell type $(\mathrm{n}=6,20.0 \%)$, mucinous type $(\mathrm{n}=5,16.7 \%)$, and mixed type $(n=1,3.3 \%)$. The total person-years of followup were 100815 person-years. The EOC IR of women treated with ovarian surgery for benign ovarian tumors was 2.98 per 10,000 person-years. Characteristics at baseline are shown in Table 1.

In term of the age on the risk of development of EOC in women after ovarian surgery for ovarian benign diseases, our results indicate that IR of EOC is consistently higher when age ranged between 30 and 39 years (IR of EOC 4.71), as well as between 40 and 49 years (IR of EOC 3.59) compared with that (IR of EOC 1.57) of the youngest group (women $<30$ years). It is interesting to find that women aged $\geq 50$ years had a lower IR of EOC (0.94 per 10,000 person-years) (Table 2).

Univariate analysis showed that only higher Charlson comorbidity index (CCI) was associated with an increasing risk for subsequent development of EOC in women after ovarian surgery for benign ovarian diseases (Table 3). As expected, TH or STH was associated with a decreased risk of subsequent development of EOC after ovarian surgery for benign ovarian diseases (Table 3). Multivariate analysis further confirmed that only higher $\mathrm{CCI}(\geq 2)$ was an important and independent risk factor associated with a significantly increased risk of subsequent development of EOC (Table 4). By contrast, hysterectomy (total or subtotal) or total removal of the ovary (BSO or BO) was not associated with the risk of subsequent development of EOC (Table 4).

\section{Discussion}

The impact of ovarian surgery for benign ovarian tumors on the subsequent risk of the developing EOC has seldom been evaluated. ${ }^{51-55}$ In this population-based cohort study using linked administrative data, we found that the EOC IR of women after ovarian surgery for benign ovarian tumor was 2.98 per 10,000 person-years, which is higher than EOC SIR of women (ranging from 0.5 to 1.0 per 10,000 person-years) in the general population in Taiwan, ${ }^{25,27,40,41,64-75}$ suggesting that ovarian surgery for any histology types of benign ovarian tumors might indeed be associated with increased subsequent development of EOC. We supposed a 3-fold to 6-fold increase if we used the EOC SIR as a reference from the general population. $^{25,27,40,41,65-77}$

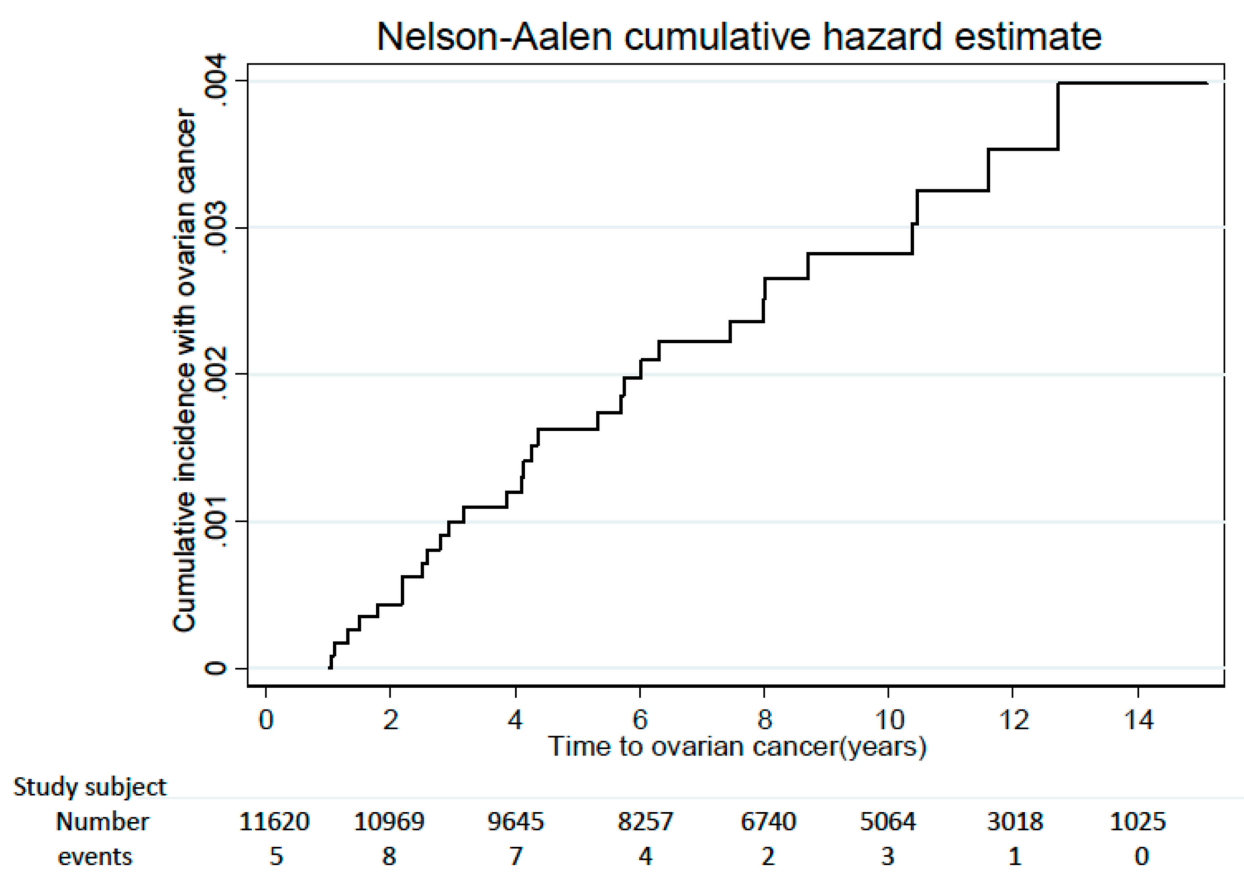

Figure 2 Accumulation number of patients developing EOC during this cohort period. 
Table I Baseline Characteristics of the Study Subjects (FollowUp Period Was 100815 Person-Years)

\begin{tabular}{|c|c|c|}
\hline Variables & Number $(n=\mid 1,620)$ & $\%$ \\
\hline \multicolumn{3}{|l|}{ Development of epithelial ovarian cancer } \\
\hline Yes & 30 & 0.26 \\
\hline No & 11,590 & 99.74 \\
\hline \multicolumn{3}{|l|}{ Socioeconomic status } \\
\hline$\geq 40,000$ & 1273 & 10.96 \\
\hline $20,000-39,999$ & 2874 & 24.73 \\
\hline$<20,000$ & 4649 & 40.01 \\
\hline Others & 2824 & 24.30 \\
\hline \multicolumn{3}{|l|}{ Work } \\
\hline Yes & 10,318 & 88.80 \\
\hline No & 1302 & 11.20 \\
\hline \multicolumn{3}{|l|}{ Urbanization } \\
\hline Urban & 3802 & 32.72 \\
\hline Suburban & 5357 & 46.10 \\
\hline Rural & 2461 & 21.18 \\
\hline \multicolumn{3}{|l|}{ Total/subtotal hysterectomy } \\
\hline Yes & 4329 & 37.25 \\
\hline No & 7291 & 62.75 \\
\hline \multicolumn{3}{|l|}{ Ovarian surgery } \\
\hline Partial oophorectomy & 7596 & 65.37 \\
\hline UO/USO \pm partial oophorectomy & 979 & 8.43 \\
\hline $\mathrm{BSO} / \mathrm{BO}$ & 3045 & 26.20 \\
\hline \multicolumn{3}{|l|}{ Repeated ovary surgery } \\
\hline Yes & 717 & 6.17 \\
\hline No & 10,903 & 93.83 \\
\hline \multicolumn{3}{|l|}{ Tubal ligation } \\
\hline Yes & 142 & 1.22 \\
\hline No & 11,478 & 98.78 \\
\hline \multicolumn{3}{|l|}{ Pelvic inflammatory disease } \\
\hline Yes & 8909 & 76.67 \\
\hline No & 2711 & 23.33 \\
\hline \multicolumn{3}{|l|}{ Infertility } \\
\hline Yes & 1168 & 10.05 \\
\hline No & 10,452 & 89.95 \\
\hline \multicolumn{3}{|l|}{ Cardiovascular disease } \\
\hline Yes & 1168 & 10.05 \\
\hline No & 10,452 & 89.95 \\
\hline \multicolumn{3}{|l|}{ Diabetes mellitus } \\
\hline Yes & 1365 & 11.75 \\
\hline No & 10,255 & 88.25 \\
\hline \multicolumn{3}{|l|}{ Chronic liver disease } \\
\hline Yes & 361 & 3.11 \\
\hline No & 11,259 & 96.89 \\
\hline \multicolumn{3}{|l|}{ Surgery confirmed ovarian endometrioma } \\
\hline Yes & 4408 & 37.93 \\
\hline No & 7212 & 62.07 \\
\hline
\end{tabular}

(Continued)
Table I (Continued).

\begin{tabular}{|l|l|l|}
\hline Variables & Number $(\mathbf{n}=\mathbf{I}$ I,620) & $\%$ \\
\hline $\begin{array}{l}\text { Rheumatic disease } \\
\text { Yes }\end{array}$ & 531 & \\
No & 11,089 & 4.57 \\
\hline Charlson comorbidity index & & 95.43 \\
0 & 5749 & \\
I & 2391 & 49.48 \\
2 & 1488 & 20.58 \\
$\geq 3$ & 1992 & 12.81 \\
\hline
\end{tabular}

Abbreviations: $\mathrm{BSO} / \mathrm{BO}$, bilateral salpingo-oophorectomy/bilateral oophorectomy; USO/UO, unilateral salpingo-oophorectomy/unilateral oophorectomy.

In Kreiger et al's study, there was no reduction of the development of subsequent EOC in women after UO, and in addition, the risk is statistically significantly increased early in the follow-up periods, with odds ratio (OR) ranging from 1.12 to $3.83 .{ }^{51}$ However, with increasing length of follow-up, the OR declined toward unity with OR ranging from 1.31 in the follow-up period between 2 years and 5 years to 0.90 in the follow-up period of more than 10 years. ${ }^{51}$ The following Chiaffarino's report also supports this concept that there was no protective role for subsequent development of EOC in women who have been treated with UO/USO (OR: $0.60,95 \%$ CI $0.3-1.4$ ) after adjustment of additional terms for education, parity, oral pill use, and family history of ovarian and breast cancer in first-degree relatives. ${ }^{52}$ However, not all data supported the increased risk of subsequent EOC in women after ovarian surgery. Earlier studies from Annegers et al in 1979 and Beard et al in 2000 showed the conflicted results, and both studies supported the protective role of oophorectomy in the reduction of subsequently developing EOC. ${ }^{53,54}$ In 2013, Melin et al suggested that radical ovarian surgery for endometriosis, including $\mathrm{UO}$ as well as complete resection of all visible endometriosis, is protective against later development of EOC ${ }^{43}$ although the potentially increasing risk of morbidity during the surgery should be reminded. ${ }^{78-97}$

In addition, clinicians might have consensus that sometimes it is hard to totally eradicate all visible or invisible lesions, including ovarian tissues, especially when the certain situations exist, such as deep infiltration endometriosis, severe adhesion between ovary and surrounding pelvic tissue or organs, which will make a total removal of ovary difficult (remnant ovarian syndrome) ${ }^{102-105}$ Moreover, these disparate results suggest that the different histology types of benign ovarian tumors should be considered in studies that 
Table 2 The Incidence Rate of Epithelial Ovarian Cancer in Women Treated with Ovarian Surgery for Benign Ovarian Diseases Based on the Different Age Status

\begin{tabular}{|c|c|c|c|c|c|}
\hline & Age $<30$ Years & Age 30-39 Years & Age 40-49 Years & Age $\geq 50$ Years & \multirow[t]{2}{*}{$\mathbf{P} *$} \\
\hline & $n=1883$ & $n=3484$ & $n=3565$ & $n=2688$ & \\
\hline Number of patients with EOC & 3 & 14 & 11 & 2 & \\
\hline Incidence per 10,000 person-years & 1.57 & 4.71 & 3.59 & 0.94 & \\
\hline Crude HR $(95 \% \mathrm{Cl})$ & I.00 (Reference) & $2.986(0.858-10.398)$ & $2.277(0.635-8.169)$ & $0.593(0.099-3.55 \mathrm{I})$ & 0.0850 \\
\hline $\mathrm{P}^{* *}$ & & 0.0857 & 0.2066 & 0.5668 & \\
\hline Adjusted HR' $(95 \% \mathrm{Cl})$ & I.00 (Reference) & $2.998(0.858-10.470)$ & $2.415(0.639-9.128)$ & $0.610(0.09 \mid-4.069)$ & 0.0964 \\
\hline $\mathrm{P}^{* *}$ & & 0.0853 & 0.1938 & 0.6095 & \\
\hline Adjusted $\mathrm{HR}^{2}(95 \% \mathrm{Cl})$ & I.00 (Reference) & $1.347(0.374-4.849)$ & $0.468(0.117-1.882)$ & $0.052(0.008-0.348)$ & $0.0002 * * *$ \\
\hline $\mathrm{P}^{* *}$ & & 0.6489 & 0.2851 & $0.0023 * *$ & \\
\hline Adjusted $\mathrm{HR}^{3}(95 \% \mathrm{Cl})$ & 1.00 (Reference) & $3.312(0.950-11.542)$ & $4.029(1.079-15.047)$ & $1.298(0.186-9.065)$ & 0.1072 \\
\hline $\mathrm{P} * *$ & & 0.0601 & $0.0382 *$ & 0.7924 & \\
\hline Adjusted $\mathrm{HR}^{4}(95 \% \mathrm{Cl})$ & I.00 (Reference) & $3.25 \mid(0.93|-| 1.352)$ & $4.062(1.051-15.707)$ & $1.200(0.157-9.160)$ & 0.0990 \\
\hline $\mathrm{P} * *$ & & 0.0646 & $0.0422 *$ & 0.8605 & \\
\hline Adjusted $\mathrm{HR}^{5}(95 \% \mathrm{Cl})$ & I.00 (Reference) & $1.540(0.431-5.504)$ & $1.076(0.265-4.364)$ & $0.142(0.020-1.013)$ & $0.0326 *$ \\
\hline $\mathrm{P} * *$ & & 0.5064 & 0.9182 & 0.0515 & \\
\hline
\end{tabular}

Notes: IR: incidence rate (incidence per 10,000 person-years); EOC: invasive epithelial ovarian cancer; HR: hazard ratio; $95 \%$ Cl: $95 \%$ confidence interval; P*: comparison among all groups. P**: comparison between study group and reference group (age < 30 years). Adjusted HR': adjustment for pelvic inflammatory disease, infertility status, cardiovascular disease, diabetes mellitus, chronic liver disease, and rheumatic disease. Adjusted $\mathrm{HR}^{2}$ : adjusted for pelvic inflammatory disease, infertility, and Charlson comorbidity index $(\mathrm{CCl})$. Adjusted $\mathrm{HR}^{3}$ : adjustment for total/subtotal hysterectomy, unilateral oophorectomy, unilateral salpingo-oophorectomy, bilateral oophorectomy, bilateral salpingo-oophorectomy, tubal ligation. Adjusted $H R^{4}$ : adjustment for conditions of $H R^{1}$ and $H R^{3}$. Adjusted $H R^{5}$ : adjustment for conditions of $H R^{2}$ and $H R^{3}$. ${ }^{*}<$ 0.05 , ** $\mathrm{P}<0.01$, *** $\mathrm{P}<0.001$.

examine the influence on EOC risk. ${ }^{80}$ As shown above, our results indicated that the initial procedure of ovarian surgery may not be associated with the decreased risk of subsequent development of EOC, even though BO or BSO was performed at the initial surgery.

Although it is hard to explain the aforementioned finding, one presumption is about the mysterious etiology of EOC. ${ }^{98-101}$ Conventionally, according to the histology, it is easy to classify EOC as serous, endometrioid, clear cell, mucinous, and other subtypes, which is also supported by some experts, such as Dr. Prat who further separated serous into high grade and low grade based on distinct histological features and molecular genetics. ${ }^{101}$ However, for a convenient way of conceptualizing different mechanisms of tumorigenesis, the dualistic classification of EOC into "type I" and "type II" is often and popularly applied in the research setting, although it may conflict with recent molecular insights of the etiology of EOC. ${ }^{98}$ The best example is the endometriosis-associated EOC (clear cell and endometrioid), which is traditionally classified as "type I", it is absence of assuming an indolent course or type I genetic profile. $^{77}$

In the current study, the distribution of histology types of EOC in women after ovarian surgery for benign ovarian tumor seemed to be similar to the data of the national population-based registry in Taiwan, ${ }^{65}$ wherein the former was compared with the latter with data showing $36.7 \%$ versus $41.4 \%$ in serous type, $20.0 \%$ versus $24.5 \%$ in mucinous type, $23.3 \%$ versus $17.5 \%$ in endometrioid type, $20 \%$ versus $13.7 \%$ in clear cell type and $3.3 \%$ versus $2.9 \%$ in others, respectively, suggesting that the subjects in the current study can be considered as part of the general population with minimal selection bias in Taiwan.

One important finding in the current study is the identification of high level of $\mathrm{CCI}(\mathrm{CCI}=2)$ as an important factor associated with a near 60 -fold increase in risk of subsequent development of EOC compared to women without CCI or lower CCI (CCI=1) (HR 59.17, 95\% CI 7.50-466.80), which was near 200-fold increase compared to those in women with no or lower $\mathrm{CCI}(\mathrm{CCI}=1)$. It suggests that when we deal with women with benign ovarian tumors who plan to undergo ovarian surgery, we should inform the subsequent risk of EOC development for those patients with higher CCI. In fact, CCI is the most used score to measure comorbidity, which is applied to a health care administrative database, and can predict relative mortality adequately. ${ }^{106-110}$ It is well known patients with higher CCI have a higher risk of surgery and/or anesthesia-associated morbidity and mortality. The current study in Danish found that patients with surgery 
Table 3 Univariate Cox Regression Analysis

\begin{tabular}{|c|c|c|c|}
\hline \multirow[t]{2}{*}{ Characteristics } & \multicolumn{3}{|c|}{ Number of Patients } \\
\hline & 11,620 & Hazard Ratio (95\% Confidence Interval) & $\mathbf{P}$ \\
\hline \multicolumn{4}{|l|}{ Endometrioma } \\
\hline No & 7212 & I (Reference) & \\
\hline Yes & 4408 & $1.714(0.838-3.507)$ & 0.1403 \\
\hline \multicolumn{4}{|l|}{ Age } \\
\hline$\leq 39$ & 5367 & I (Reference) & \\
\hline$>39$ & 6253 & $0.716(0.348-1.475)$ & 0.3654 \\
\hline \multicolumn{4}{|l|}{ Total /subtotal hysterectomy } \\
\hline No & 7291 & I (Reference) & \\
\hline Yes & 4329 & $0.252(0.088-0.722)$ & $0.0103 *$ \\
\hline Ovarian surgery & & & 0.2753 \\
\hline $\mathrm{BSO} / \mathrm{BO}$ & 3045 & I (Reference) & \\
\hline UO/USO \pm partial oophorectomy & 979 & $3.047(0.546-16.988)$ & 0.2038 \\
\hline Partial oophorectomy & 7596 & $2.253(0.782-6.494)$ & 0.1327 \\
\hline \multicolumn{4}{|l|}{ Tubal ligation } \\
\hline No & 11,478 & I (Reference) & \\
\hline Yes & 142 & 0 & 0.9847 \\
\hline \multicolumn{4}{|l|}{ Pelvic inflammatory disease } \\
\hline No & 2711 & I (Reference) & \\
\hline Yes & 8909 & $0.942(0.404-2.195)$ & 0.8892 \\
\hline \multicolumn{4}{|l|}{ Infertility } \\
\hline No & 10,452 & I (Reference) & \\
\hline Yes & 1168 & $1.805(0.69 \mid-4.715)$ & 0.2282 \\
\hline \multicolumn{4}{|l|}{ Cardiovascular disease } \\
\hline No & 10,452 & I (Reference) & \\
\hline Yes & 1168 & $0.584(0.139-2.452)$ & 0.4626 \\
\hline \multicolumn{4}{|l|}{ Diabetes mellitus } \\
\hline No & 10,255 & I (Reference) & \\
\hline Yes & 1365 & $1.086(0.379-3.112)$ & 0.8781 \\
\hline \multicolumn{4}{|l|}{ Chronic liver disease } \\
\hline No & 11,259 & I (Reference) & \\
\hline Yes & 361 & 0 & 0.9843 \\
\hline \multicolumn{4}{|l|}{ Rheumatic disease } \\
\hline No & 11,089 & I (Reference) & \\
\hline Yes & 531 & $1.423(0.339-5.972)$ & 0.6302 \\
\hline Charlson comorbidity index & & & $0.0017^{* *}$ \\
\hline 0 & 5749 & I (Reference) & \\
\hline 1 & 2391 & 0 & 0.9880 \\
\hline 2 & 1488 & $37.531(4.804-293.193)$ & $0.0005 * * *$ \\
\hline$\geq 3$ & 1992 & $53.484(7.160-399.531)$ & $0.000 I^{* * *}$ \\
\hline
\end{tabular}

Notes: $* \mathrm{P}<0.05, * * \mathrm{P}<0.01, * * * \mathrm{P}<0.001$.

Abbreviations: BSO/BO, bilateral salpingo-oophorectomy/bilateral oophorectomy; USO/UO, unilateral salpingo-oophorectomy/unilateral oophorectomy.

for hip fracture in a high level of CCI $(\geq 3)$ had a significantly higher risk of reoperation (HR 2.36, 95\% CI 1.19-4.69). ${ }^{1,19}$ Our results also found that patients with a high level of CCI indeed have a statistically significantly higher risk of subsequent development of EOC after ovarian surgery for benign ovarian tumors. Therefore, if the 
Table 4 Multivariate Cox Regression Analysis

\begin{tabular}{|c|c|c|c|}
\hline \multirow[t]{2}{*}{ Characteristics } & \multicolumn{3}{|c|}{ Number of Patients } \\
\hline & 11,620 & Hazard Ratio (95\% Confidence Interval) & $\mathbf{P}$ \\
\hline \multicolumn{4}{|l|}{ Endometrioma } \\
\hline No & 7212 & I (Reference) & \\
\hline Yes & 4408 & $1.007(0.445-2.278)$ & 0.9866 \\
\hline \multicolumn{4}{|l|}{ Age } \\
\hline$\leq 39$ & 5367 & I (Reference) & \\
\hline$>39$ & 6253 & $0.880(0.346-2.235)$ & 0.7873 \\
\hline \multicolumn{4}{|l|}{ Total/subtotal hysterectomy } \\
\hline No & 7291 & I (Reference) & \\
\hline Yes & 4329 & $0.362(0.08|-1.6| 4)$ & 0.1826 \\
\hline \multicolumn{4}{|l|}{ Ovarian surgery } \\
\hline $\mathrm{BSO} / \mathrm{BO}$ & 3045 & I (Reference) & \\
\hline UO/USO \pm partial oophorectomy & 979 & $2.122(0.304-14.824)$ & 0.4482 \\
\hline Partial oophorectomy & 7596 & $0.883(0.195-3.998)$ & 0.8722 \\
\hline \multicolumn{4}{|l|}{ Tubal ligation } \\
\hline No & 11,478 & & \\
\hline Yes & 142 & & \\
\hline \multicolumn{4}{|l|}{ Pelvic inflammatory disease } \\
\hline No & 2711 & I (Reference) & \\
\hline Yes & 8909 & $0.760(0.301-1.920)$ & 0.5622 \\
\hline \multicolumn{4}{|l|}{ Infertility } \\
\hline No & 10,452 & I (Reference) & \\
\hline Yes & 1168 & $1.387(0.478-4.025)$ & 0.5469 \\
\hline Charlson comorbidity index & & & $0.0017^{* *}$ \\
\hline 0 & 5749 & I (Reference) & \\
\hline 1 & 2391 & 0 & 0.9882 \\
\hline 2 & 1488 & 59.165 (7.499-466.804) & $0.0001 * * *$ \\
\hline$\geq 3$ & 1992 & $190.679(24.333-1494.186)$ & $<0.000 I^{* * *}$ \\
\hline
\end{tabular}

Notes: $* * \mathrm{P}<0.01$, ***P $<0.001$

Abbreviations: BSO/BO, bilateral salpingo-oophorectomy/bilateral oophorectomy; USO/UO, unilateral salpingo-oophorectomy/unilateral oophorectomy.

future fertility is not required anymore, the need for additional total/subtotal hysterectomy plus oophorectomy and/ or salpingectomy or salpingo-oophorectomy could be discussed to weigh the ratio of risk and benefit. ${ }^{79-97}$

In the current study, however, adding total/subtotal hysterectomy to the benign ovarian surgery was not associated with a risk reduction on the subsequent development of EOC after ovarian surgery. This finding argued against a long-term belief that hysterectomy with/without oophorectomy can protect against EOC effectively, ${ }^{51-55}$ but supported the results obtained from studies challenging aforementioned long-held belief, including a recent population-based record-linkage study by Dixon-Suen et $\mathrm{al}^{12}$ and a recent meta-analysis by Wang et al. ${ }^{81}$ Dr. Dixon-
Suen et al showed that hysterectomy alone was not associated with risk of EOC overall (HR 0.98, 95 CI 0.851.11) or with the risk of most common serous subtype (HR $1.05,95 \%$ CI $0.89-1.23$ ), suggesting that substantial alternation of EOC risk can not be achieved by hysterectomy with ovarian conservation for most women. ${ }^{12}$

Finally, we evaluated the relationship between age and EOC risk, considering age as an important factor for the development of EOC. ${ }^{12,13,20,23,24,40,41}$ Different from our previous studies, ${ }^{40,41}$ EOC IR remained consistent in women aged between 30 and 50 years (Table 2). EOC IR in the younger population (age $<30$ years) and elder population (age $\geq 50$ years) was low. It can be explained by the relatively conservative surgery in women during reproductive age due 
to fertility need. By contrast, when peri-/post-menopausal women a need ovarian surgery, the procedure of $\mathrm{TH} / \mathrm{STH}$ and BSO could always be taken into consideration despite the benign nature.

The strength of the current study includes a large population-based cohort study, Asian population, Chinese population, enrolled subjects who have been treated with ovarian surgery for benign ovarian tumor (definite operation procedure), chronic medical illness (CCI), and infertility or pelvic inflammatory disease.

However, there are some limitations. First, except endometrioma, other subtypes of benign ovarian tumors were not further stratified. Second, the specific reason (indication) for ovarian surgery was not available. For example, the torsion of the ovary as an emergency might be an indication of ovarian surgery, but the relevant information was not available in the database. However, our data were obtained from the Taiwanese NHI program, of which the data could not be included if no pathology was performed. In addition, we also exclude those who do not have a pathology report, which has been shown in Figure 1. Third, the size of the cyst has not been included. Fourth, only a small number of EOC developed during the follow-up period, limiting the precision of our risk estimates in the study. However, this limitation might be due to the low incidence rate of this targeted disease (EOC). Additionally, compared with previous studies with a large sample size, only 10 cases of EOC occurred during the 10year follow-up period. ${ }^{96}$ In the Japanese study, during the follow-up period, only 4 cases developed subsequent EOC after ovarian surgery. ${ }^{56}$ Recently, Murakami et al summarized 32 published articles to monitor the risk of EOC from ovarian endometrial cysts and only identified 79 cases. ${ }^{26}$ The relatively long interval between enrollment in the cohort and the diagnosis of an EOC, along with the exclusion of those subjects with a diagnosis of invasive EOC within 365 days after ovarian surgery for benign ovarian tumors, suggest that the observed increase in risk was not the preexisting tumors themselves. Finally, we had neither profile of gene (for example, BRCA status) nor the data of parity, and also did not have information about the detailed of infertility and other surgery or medication history, such as oral contraceptive, hormone therapy in the database, all of which are associated with the increased or decreased risk of development of EOC. ${ }^{111-115}$ In Taiwan, the examination of BRCA status is not covered by insurance of the Taiwan Bureau of National Health Insurance and Ministry of Health and Welfare. There are many current clinical studies showing better outcomes in EOC patients with BRCA1/BRCA2 mutants after maintenance therapy of PARP inhibitors. ${ }^{6-9,116}$

The lack of cost-effective screening method and unavoidable worst prognosis while EOC is diagnosed remind us of the consideration of using prevention strategy to decrease the occurrence of EOC. Identification of risk factors for the development of EOC can further augment the effects to decrease EOC-related morbidity and/or mortality. In the current study, we disclosed women with higher comorbidity ( $\mathrm{CCI} \geq 2$ ) disease undergoing ovarian surgery for benign ovarian tumors indeed have a higher risk of subsequent development of EOC. Based on the aforementioned findings, we commend that risk/benefit ratio should be balanced carefully, because this increased risk not only relies on how well we help with prevention of subsequent development of EOC, but also depends on how accurately we protect patients from the danger of a false-positive result (benign ovarian tumors-associated overtreatment and following morbidity and mortality).

\section{Acknowledgments}

This study was based in part on data from the Taiwan National Health Insurance Research Database provided by the National Health Insurance Administration, Ministry of Health and Welfare and managed by National Health Research Institutes. The interpretations and conclusions contained herein do not represent those of the National Health Insurance Administration, Ministry of Health and Welfare or National Health Research Institutes.

This study was supported in part by grants from the Ministry of Science and Technology (MOST 106-2314B-075-061-MY3) and the Taipei Veterans General Hospital (Grant VGH109E-005, VGH109C-108 and VGH109A-022), Taipei, Taiwan. The authors also appreciate very much financial support from the Female Cancer Foundation, Taipei, Taiwan. The funders had no role in study design, data collection and analysis, decision to publish, or preparation of the manuscript. No additional external funding was received for this study.

\section{Author Contributions}

All authors contributed to data analysis, drafting and revising the article, gave final approval of the version to be published, and agree to be accountable for all aspects of the work.

\section{Disclosure}

The authors report no conflicts of interest in this work. 


\section{References}

1. Chandra A, Pius C, Nabeel M, et al. Ovarian cancer: current status and strategies for improving therapeutic outcomes. Cancer Med. 2019;8(16):7018-7031. doi:10.1002/cam4.2560

2. Stenzel AE, Buas MF, Moysich KB. Survival disparities among racial/ethnic groups of women with ovarian cancer: an update on data from the Surveillance, Epidemiology and End Results (SEER) registry. Cancer Epidemiol. 2019;62:101580. doi:10.1016/j.canep. 2019.101580

3. Liu $\mathrm{CH}$, Horng HC, Wang PH. A case of ovarian cancer present with acute respiratory distress: spontaneous rupture of diaphragm. Taiwan J Obstet Gynecol. 2019;58(5):712-714. doi:10.1016/j. tjog.2019.07.024

4. Lheureux S, Gourley C, Vergote I, Oza AM. Epithelial ovarian cancer. Lancet. 2019;393(10177):1240-1253. doi:10.1016/S01406736(18)32552-2

5. Vergote I, Coens C, Nankivell M, et al. EORTC; MRC CHORUS study investigators. Neoadjuvant chemotherapy versus debulking surgery in advanced tubo-ovarian cancers: pooled analysis of individual patient data from the EORTC 55971 and CHORUS trials. Lancet Oncol. 2018;19(12):1680-1687. doi:10.1016/S14702045(18)30566-7

6. González-Martín A, Pothuri B, Vergote I, et al. PRIMA/ENGOTOV26/GOG-3012 Investigators. Niraparib in patients with newly diagnosed advanced ovarian cancer. N Engl J Med. 2019. doi:10.1056/NEJMoa1910962

7. Coleman RL, Fleming GF, Brady MF, et al. Veliparib with first-line chemotherapy and as maintenance therapy in ovarian cancer. $N$ Engl J Med. 2019;381(25):2403-2415. doi:10.1056/NEJMoa1909707

8. Mateo J, Lord CJ, Serra V, et al. A decade of clinical development of PARP inhibitors in perspective. Ann Oncol. 2019;30(9):14 37-1447. doi:10.1093/annonc/mdz192

9. Naumann RW, Coleman RL, Brown J, Moore KN. Phase III trials in ovarian cancer: the evolving landscape of front line therapy. Gynecol Oncol. 2019;153(2):436-444. doi:10.1016/j.ygyno.2019.02.008

10. Chikazawa K, Netsu S, Kuwata T, Konno R. Bevacizumab improves overall survival in platinum refractory ovarian cancer patients: A retrospective study. Taiwan J Obstet Gynecol. 2018;57 (6):819-824. doi:10.1016/j.tjog.2018.10.00

11. Wang PH. Neoadjuvant chemotherapy before definite operative approach for women with advanced-stage epithelial ovarian cancer. Taiwan J Obstet Gynecol. 2018;57(5):623-624. doi:10.10 16/j.tjog.2018.08.001

12. Dixon-Suen SC, Webb PM, Wilson LF, Tuesley K, Stewart LM, Jordan SJ. The Association between hysterectomy and ovarian cancer risk: A population-based record-linkage study. J Natl Cancer Inst. 2019;111(10):1097-1103. doi:10.1093/jnci/djz015

13. Vassard D, Schmidt L, Glazer CH, Lyng Forman J, KamperJørgensen M, Pinborg A. Assisted reproductive technology treatment and risk of ovarian cancer-a nationwide population-based cohort study. Hum Reprod. 2019;34(11):2290-2296.pii: dez165. doi:10.1093/humrep/dez165

14. Stentz NC, Koelper N, Barnhart KT, Sammel MD, Senapati S. Infertility and Mortality. Am J Obstet Gynecol. 2019;pii: S00029378(19):31112-31113. doi:10.1016/j.ajog.2019.09.007

15. Cristiano S, Leal A, Phallen J, et al. Genome-wide cell-free DNA fragmentation in patients with cancer. Nature. 2019;570 (7761):385-389. doi:10.1038/s41586-019-1272-6

16. Sundbøll J, Thygesen SK, Veres K, et al. Risk of cancer in patients with constipation. Clin Epidemiol. 2019;11:299-310. doi:10.2147/ CLEP.S205957

17. van Lieshout LAM, Steenbeek MP, De Hullu JA, et al. Hysterectomy with opportunistic salpingectomy versus hysterectomy alone. Cochrane Database Syst Rev. 2019;8:CD012858. doi:10.1002/14651858.CD012858.pub2
18. Wheeler LJ, Desanto K, Teal SB, Sheeder J, Guntupalli SR. Intrauterine device use and ovarian cancer risk: a systematic review and meta-analysis. Obstet Gynecol. 2019;134(4):791-800. doi:10. 1097/AOG.0000000000003463

19. Nelson HD, Pappas M, Cantor A, Haney E, Holmes R. Risk assessment, genetic counseling, and genetic testing for brca-related cancer in women. JAMA. 2019;322(7):666-685. doi:10.1001/jama.2019.8430

20. Yarmolinsky J, Relton CL, Lophatananon A, et al. Appraising the role of previously reported risk factors in epithelial ovarian cancer risk: a Mendelian randomization analysis. PLoS Med. 2019;16(8): e1002893. doi:10.1371/journal.pmed.1002893

21. Owens DK, Davidson KW, Krist AH, et al.; US Preventive Services Task Force. Risk assessment, genetic counseling, and genetic testing for BRCA-related cancer. JAMA. 2019;322 (7):652-665. doi:10.1001/jama.2019.10987

22. Zheng G, Chattopadhyay S, Försti A, Sundquist K, Hemminki K. Familial risks of second primary cancers and mortality in ovarian cancer patients. Clin Epidemiol. 2018;10:1457-1466. doi:10.2147/ CLEP.S174173

23. Mallen A, Soong TR, Townsend MK, Wenham RM, Crum CP, Tworoger SS. Surgical prevention strategies in ovarian cancer. Gynecol Oncol. 2018;151(1):166-175. doi:10.1016/j.ygyno.2018. 08.005

24. Koushik A, Grundy A, Abrahamowicz M, et al. Hormonal and reproductive factors and the risk of ovarian cancer. Cancer Causes Control. 2017;28(5):393-403. doi:10.1007/s10552-016-0848-9

25. Lee WL, Chang WH, Wang KC, et al. The risk of epithelial ovarian cancer of women with endometriosis may be varied greatly if diagnostic criteria are different: a nationwide population-based cohort study. Medicine (Baltimore). 2015;94(39):e1633. doi:10.10 97/MD.0000000000001633

26. Murakami K, Kotani Y, Shiro R, Takaya H, Nakai H, Matsumura N. Endometriosis-associated ovarian cancer occurs early during follow-up of endometrial cysts. Int $J$ Clin Oncol. 2020;25(1):51-58. doi:10.1007/s10147-019-01536-5

27. Su KM, Wang PH, Yu MH, Chang CM, Chang CC. The recent progress and therapy in endometriosis-associated ovarian cancer. $J$ Chin Med Assoc. 2020;83(3):227-232. doi:10.1097/JCMA.000 0000000000262

28. Hsu HC, Tseng KY, Wang HC, Sung FC, Ma WF. Risk of endometriosis and subsequent ovary and breast cancers in nurses: a population-based cohort study in Taiwan. Int $J$ Environ Res Public Health. 2019;16(18):3469. doi:10.3390/ijerph16183469

29. Sapalidis K, Machairiotis N, Zarogoulidis P, et al. Genes' interactions: a major contributor to the malignant transformation of endometriosis. Int J Mol Sci. 2019;20(8):1842. doi:10.3390/ijms20 081842

30. Bulun SE, Yilmaz BD, Sison C, et al. Endometriosis. Endocr Rev. 2019;40(4):1048-1079. doi:10.1210/er.2018-00242

31. Bulun SE, Wan Y, Matei D. Epithelial mutations in endometriosis: link to ovarian cancer. Endocrinology. 2019;160(3):626-638. doi:10.1210/en.2018-00794

32. Kajiyama H, Suzuki S, Yoshihara M, et al. Endometriosis and cancer. Free Radic Biol Med. 2019;133:186-192. doi:10.1016/j. freeradbiomed.2018.12.015

33. Lee WL, Wang PH. Aberrant sialylation in ovarian cancers. JChin Med Assoc. 2020;83(4):337-344. doi:10.1097/JCMA.0000000000000252.

34. Parazzini F, Esposito G, Tozzi L, Noli S, Bianchi S. Epidemiology of endometriosis and its comorbidities. Eur J Obstet Gynecol Reprod Biol. 2017;209:3-7. doi:10.1016/j.ejogrb.2016.04.021

35. Teng SW, Horng HC, Ho CH, Yen MS, Chao HT, Wang PH. Taiwan association of gynecology systematic review group. women with endometriosis have higher comorbidities: analysis of domestic data in Taiwan. J Chin Med Assoc. 2016;79(11):577-582. doi:10.1016/j.jcma.2016.04.006 
36. Li J, Liu R, Tang S, et al. Impact of endometriosis on risk of ovarian, endometrial and cervical cancers: a meta-analysis. Arch Gynecol Obstet. 2019;299(1):35-46. doi:10.1007/s00404-018-4968-1

37. Poole EM, Lin WT, Kvaskoff M, De Vivo I, Terry KL, Missmer SA. Endometriosis and risk of ovarian and endometrial cancers in a large prospective cohort of U.S. nurses. Cancer Causes Control. 2017;28(5):437-445. doi:10.1007/s10552-017-0856-4

38. Guo SW. Endometriosis and ovarian cancer: potential benefits and harms of screening and risk-reducing surgery. Fertil Steril. 2015;104(4):813-830. doi:10.1016/j.fertnstert.2015.08.006

39. Burghaus S, Häberle L, Schrauder MG, et al. Endometriosis as a risk factor for ovarian or endometrial cancer - results of a hospital-based case-control study. BMC Cancer. 2015;15(1):751. doi:10.1186/s12885-015-1821-9

40. Chang WH, Wang KC, Lee WL, et al. Endometriosis and the subsequent risk of epithelial ovarian cancer. Taiwan J Obstet Gynecol. 2014;53(4):530-535. doi:10.1016/j.tjog.2014.04.025

41. Wang $\mathrm{KC}$, Chang $\mathrm{WH}$, Lee $\mathrm{WL}$, et al. An increased risk of epithelial ovarian cancer in Taiwanese women with a new surgico-pathological diagnosis of endometriosis. BMC Cancer. 2014;14(1):831. doi:10.1186/1471-2407-14-831

42. Buis CC, van Leeuwen FE, Mooij TM, Burger CW, OMEGA Project Group. Increased risk for ovarian cancer and borderline ovarian tumours in subfertile women with endometriosis. Hum Reprod. 2013;28(12):3358-3369. doi:10.1093/humrep/det340

43. Melin AS, Lundholm $\mathrm{C}$, Malki N, Swahn ML, Sparèn $\mathrm{P}$, Bergqvist A. Hormonal and surgical treatments for endometriosis and risk of epithelial ovarian cancer. Acta Obstet Gynecol Scand. 2013;92(5):546-554. doi:10.1111/aogs.12123

44. Pearce CL, Templeman C, Rossing MA, et al. Ovarian cancer association consortium. association between endometriosis and risk of histological subtypes of ovarian cancer: a pooled analysis of case-control studies. Lancet Oncol. 2012;13(4):385-394. doi:10.1016/S1470-2045(11)70404-1

45. Olson JE, Cerhan JR, Janney CA, Anderson KE, Vachon CM, Sellers TA. Postmenopausal cancer risk after self-reported endometriosis diagnosis in the iowa women's health study. Cancer. 2002;94(5):1612-1618. doi:10.1002/cncr.10370

46. Lai KM, Chen TL, Chang CC, Chen HH, Lee YW. Association between NSAID use and mortality risk in patients with end-stage renal disease: a population-based cohort study. Clin Epidemiol. 2019;11:429-441. doi:10.2147/CLEP.S204322

47. Harnod T, Lin CL, Kao CH. Epilepsy is associated with higher subsequent mortality risk in patients after stroke: a population-based cohort study in Taiwan. Clin Epidemiol. 2019;11:247-255. doi:10.2147/CLEP.S201263

48. Chan IC, Lee YS, Chuang CM, Soong WJ. The influence of pleurodesis on the outcome of primary spontaneous pneumothorax in children. J Chin Med Assoc. 2019;82(4):305-311. doi:10.1097/ JCMA.0000000000000073

49. Li JY, Wang PH, Vitale SG, et al. Pregnancy-induced hypertension is an independent risk factor for meconium aspiration syndrome: a retrospective population based cohort study. Taiwan J Obstet Gynecol. 2019;58(3):396-400. doi:10.1016/j.tjog.2018.11.034

50. Chen SN, Wang PH, Hsieh MF, Tsai HW, Lin LT, Tsui KH. Maternal pregnancy-induced hypertension increases the subsequent risk of neonatal candidiasis: a nationwide population-based cohort study. Taiwan J Obstet Gynecol. 2019;58(2):261-265. doi:10.1016/ j.tjog.2019.01.017

51. Kreiger N, Sloan M, Cotterchio M, Parsons P. Surgical procedures associated with risk of ovarian cancer. Int J Epidemiol. 1997;26 (4):710-715. doi:10.1093/ije/26.4.710

52. Chiaffarino F, Parazzini F, Decarli A, et al. Hysterectomy with or without unilateral oophorectomy and risk of ovarian cancer Gynecol Oncol. 2005;97(2):318-322. doi:10.1016/j.ygyno.2005. 01.030
53. Annegers JF, Strom H, Decker DG, Dockerty MB, O'Fallon WM. Ovarian cancer: incidence and case-control study. Cancer. 1979;43 (2):723-729. doi:10.1002/1097-0142(197902)43:2<723::aid-cncr 2820430248>3.0.co;2-1

54. Beard CM, Hartmann LC, Atkinson EJ, et al. The epidemiology of ovarian cancer: a population-based study in Olmsted County, Minnesota, 1935-1991. Ann Epidemiol. 2000;10(1):14-23. doi:10. 1016/s1047-2797(99)00045-9

55. Rossing MA, Cushing-Haugen KL, Wicklund KG, Doherty JA, Weiss NS. Risk of epithelial ovarian cancer in relation to benign ovarian conditions and ovarian surgery. Cancer Causes Control. 2008;19(10):1357-1364. doi:10.1007/s10552-008-9207-9

56. Haraguchi H, Koga K, Takamura M, et al. Development of ovarian cancer after excision of endometrioma. Fertil Steril. 2016;106 (6):1432-1437.e2. doi:10.1016/j.fertnstert.2016.07.1077

57. Chan $\mathrm{CH}$, Yang SF, Yeh HW, et al. Risk of pneumonia in patients with burn injury: a population-based cohort study. Clin Epidemiol. 2018;10:1083-1091. doi:10.2147/CLEP.S172980

58. Chi NF, Kuan YC, Huang YH, et al. Development and validation of risk score to estimate 1-year late poststroke epilepsy risk in ischemic stroke patients. Clin Epidemiol. 2018;10:1001-1011. doi: $10.2147 /$ CLEP.S168169

59. Liu FC, Lin HT, Kuo CF, Hsieh MY, See LC, Yu HP. Familial aggregation of Parkinson's disease and coaggregation with neuropsychiatric diseases: a population-based cohort study. Clin Epidemiol. 2018;10:631-641. doi:10.2147/CLEP.S164330

60. Chang WS, Lin LT, Hsu LC, Tang PL, Tsui KH, Wang PH. Maternal pregnancy-induced hypertension increases the subsequent risk of transient tachypnea of the newborn: a nationwide population-based cohort study. Taiwan J Obstet Gynecol. 2018;57 (4):546-550. doi:10.1016/j.tjog.2018.06.013

61. Liao HT, Lin MC, Tsai CY, Hsu CY, Wu TH. Renal transplantation delays major adverse cardiac events (MACEs) in patients with end-stage renal disease: a nationwide population-based study. J Chin Med Assoc. 2018;81(9):766-771. doi:10.1016/j.jcma.2018.04.003

62. Lin TK, Liou YS, Lin CH, Chou P, Jong GP. High-potency statins but not all statins decrease the risk of new-onset osteoporotic fractures: a nationwide population-based longitudinal cohort study. Clin Epidemiol. 2018;10:159-165. doi:10.2147/CLEP.S14 5311

63. Huang BS, Chang WH, Wang $\mathrm{KC}$, et al. Endometriosis might be inversely associated with developing chronic kidney disease: a population-based cohort study in Taiwan. Int J Mol Sci. 2016;17 (7):1079. doi:10.3390/ijms 17071079

64. Tavassoeli FA. World Health Organization Classification of Tumours: Pathology and Genetics of Tumours of the Breast and Female Genital Organs. Lyon: IARC press; 2003.

65. Chiang YC, Chen CA, Chiang CJ, et al. Trends in incidence and survival outcome of epithelial ovarian cancer: 30-year national population-based registry in Taiwan. J Gynecol Oncol. 2013;24 (4):342-351. doi:10.3802/jgo.2013.24.4.342

66. Tseng JJ, Huang CC, Chiang HY, Chen YH, Lin CH. Prior uterine myoma and risk of ovarian cancer: a population-based case-control study. J Gynecol Oncol. 2019;30(5):e72. doi:10.3802/jgo.2019.30.e72

67. Ding DC, Chen W, Wang JH, Lin SZ. Association between polycystic ovarian syndrome and endometrial, ovarian, and breast cancer: a population-based cohort study in Taiwan. Medicine (Baltimore). 2018;97(39):e12608. doi:10.1097/MD.0000000000012608

68. Chang LC, Huang CF, Lai MS, Shen LJ, Wu FL, Cheng WF. Prognostic factors in epithelial ovarian cancer: a population-based study. PLoS One. 2018;13(3):e0194993. doi:10.1371/journal.pone. 0194993

69. Kamiza AB, Su FH, Wang WC, Sung FC, Chang SN, Yeh CC. Chronic hepatitis infection is associated with extrahepatic cancer development: a nationwide population-based study in Taiwan. BMC Cancer. 2016;16(1):861. doi:10.1186/s12885-016-2918-5 
70. Shen CC, Hu LY, Yang AC, Chiang YY, Hung JH, Tsai SJ. Risk of uterine, ovarian and breast cancer following pelvic inflammatory disease: a nationwide population-based retrospective cohort study. BMC Cancer. 2016;16(1):839. doi:10.1186/s12885-016-2857-1

71. Kok VC, Tsai HJ, Su CF, Lee CK. The risks for ovarian, endometrial, breast, colorectal, and other cancers in women with newly diagnosed endometriosis or adenomyosis: a population-based study. Int J Gynecol Cancer. 2015;25(6):968-976. doi:10.1097/ IGC.0000000000000454

72. Yu HC, Lin CY, Chang WC, Shen BJ, Chang WP, Chuang CM. Task force on carcinogenesis of endometrial cancer. increased association between endometriosis and endometrial cancer: a nationwide population-based retrospective cohort study. Int J Gynecol Cancer. 2015;25(3):447-452. doi:10.1097/IGC.00 00000000000384

73. Shen CC, Yang AC, Hung JH, Hu LY, Tsai SJ. A nationwide population-based retrospective cohort study of the risk of uterine, ovarian and breast cancer in women with polycystic ovary syndrome. Oncologist. 2015;20(1):45-49. doi:10.1634/theoncologist.2014-0311

74. Hsu PC, Lin WH, Kuo TH, Lee HM, Kuo C, Li CY. A population-based cohort study of all-cause and site-specific cancer incidence among patients with type 1 diabetes mellitus in Taiwan. J Epidemiol. 2015;25(9):567-573. doi:10.2188/jea.JE20140197

75. Chen HF, Chang YH, Ko MC, Li CY. A large scale population-based cohort study on the risk of ovarian neoplasm in patients with type 2 diabetes mellitus. Gynecol Oncol. 2014;134 (3):576-580. doi:10.1016/j.ygyno.2014.07.001

76. Wu MP, Wu CJ, Long CY, et al. Surgical trends for benign ovarian tumors among hospitals of different accreditation levels: an 11-year nationwide population-based descriptive study in Taiwan. Taiwan J Obstet Gynecol. 2013;52(4):498-504. doi:10.1016/j.tjog.2013.10.008

77. Lin HW, Tu YY, Lin SY, et al. Risk of ovarian cancer in women with pelvic inflammatory disease: a population-based study. Lancet Oncol. 2011;12(9):900-904. doi:10.1016/S1470-2045(11)70165-6

78. Shih CY, Lai CR, Huang CY, Twu NF, Chao KC, Wang PH. A challenge in the management of a patient with ovarian cancer associated with extensive endometriosis. Taiwan J Obstet Gynecol. 2012;51(2):324-325. doi:10.1016/j.tjog.2012.04.035

79. Evans EC, Matteson KA, Orejuela FJ, et al. Society of gynecologic surgeons systematic review group. salpingo-oophorectomy at the time of benign hysterectomy: a systematic review. Obstet Gynecol. 2016;128(3):476-485. doi:10.1097/AOG.0000000000001592

80. Wentzensen N, Poole EM, Trabert B, et al. Ovarian cancer risk factors by histologic subtype: an analysis from the ovarian cancer cohort consortium. J Clin Oncol. 2016;34(24):2888-2898. doi:10.1200/JCO.2016.66.8178

81. Wang C, Liang Z, Liu X, Zhang Q, Li S. The association between endometriosis, tubal ligation, hysterectomy and epithelial ovarian cancer: meta-analyses. Int J Environ Res Public Health. 2016;13 (11):1138. doi:10.3390/ijerph13111138

82. Zhang Y, Qu P. Factors associated with ovarian endometriosis malignancy and its recurrence in Chinese women. J Obstet Gynaecol. 2019;39(8):1148-1153. doi:10.1080/01443615.2019.16 03209

83. Saraswat L, Ayansina D, Cooper KG, Bhattacharya S, Horne AW, Bhattacharya S. Impact of endometriosis on risk of further gynaecological surgery and cancer: a national cohort study. BJOG. 2018;125(1):64-72. doi:10.1111/1471-0528.14793

84. Matthews CA. Management strategies for the ovaries at the time of hysterectomy for benign disease. Obstet Gynecol Clin North Am. 2016;43(3):539-549. doi:10.1016/j.ogc.2016.04.011

85. Mikhail E, Salemi JL, Mogos MF, Hart S, Salihu HM, Imudia AN. National trends of adnexal surgeries at the time of hysterectomy for benign indication, United States, 1998-2011. Am J Obstet Gynecol. 2015;213(5):713.e1-13. doi:10.1016/j.ajog.2015.04.031
86. Rice MS, Hankinson SE, Tworoger SS. Tubal ligation, hysterectomy, unilateral oophorectomy, and risk of ovarian cancer in the Nurses' Health Studies. Fertil Steril. 2014;102(1):192-198.e3. doi:10.1016/j.fertnstert.2014.03.041

87. Orozco LJ, Tristan M, Vreugdenhil MM, Salazar A. Hysterectomy versus hysterectomy plus oophorectomy for premenopausal women. Cochrane Database Syst Rev. 2014;7:CD005638. doi:10. 1002/14651858.CD005638.pub3

88. Gaudet MM, Gapstur SM, Sun J, Teras LR, Campbell PT, Patel AV. Oophorectomy and hysterectomy and cancer incidence in the cancer prevention study-ii nutrition cohort. Obstet Gynecol. 2014;123 (6):1247-1255. doi:10.1097/AOG.0000000000000270

89. Obermair A, Youlden DR, Baade PD, Janda M. The impact of riskreducing hysterectomy and bilateral salpingo-oophorectomy on survival in patients with a history of breast cancer-a populationbased data linkage study. Int J Cancer. 2014;134(9):2211-2222. doi:10.1002/ijc. 28537

90. McAlpine JN, Hanley GE, Woo MM, et al. Ovarian Cancer research program of british columbia. opportunistic salpingectomy: uptake, risks, and complications of a regional initiative for ovarian cancer prevention. Am J Obstet Gynecol. 2014;210(5):471.e1-11. doi:10.1016/j.ajog.2014.01.003

91. Vorwergk J, Radosa MP, Nicolaus K, et al. Prophylactic bilateral salpingectomy (PBS) to reduce ovarian cancer risk incorporated in standard premenopausal hysterectomy: complications and re-operation rate. J Cancer Res Clin Oncol. 2014;140(5):85 9-865. doi:10.1007/s00432-014-1622-6

92. Harmanli O, Shinnick J, Jones K, St Marie P. Obstetriciangynecologists' opinions on elective bilateral oophorectomy at the time of hysterectomy in the United States: a nationwide survey. Menopause. 2014;21(4):355-360. doi:10.1097/GME.0b013e31829fc376

93. Boggs DA, Palmer JR, Rosenberg L. Bilateral oophorectomy and risk of cancer in African American women. Cancer Causes Control. 2014;25(4):507-713. doi:10.1007/s10552-014-0353-y

94. Larson CA. Prophylactic bilateral oophorectomy at time of hysterectomy for women at low risk: ACOG revises practice guidelines for ovarian cancer screening in low-risk women. Curr Oncol. 2014;21(1):9-12. doi:10.3747/co.21.1721

95. Jordan SJ, Nagle CM, Coory MD, et al. Has the association between hysterectomy and ovarian cancer changed over time? A systematic review and meta-analysis. Eur J Cancer. 2013;49 (17):3638-3647. doi:10.1016/j.ejca.2013.07.005

96. Rice MS, Murphy MA, Tworoger SS. Tubal ligation, hysterectomy and ovarian cancer: A meta-analysis. J Ovarian Res. 2012;5(1):13. doi:10.1186/1757-2215-5-13

97. Rice MS, Murphy MA, Vitonis AF, et al. Tubal ligation, hysterectomy and epithelial ovarian cancer in the New England Case-Control Study. Int J Cancer. 2013;133(10):2415-2421. doi:10.1002/ijc.28249

98. Salazar C, Campbell IG, Gorringe KL. When is "type I" ovarian cancer not "type I"? Indications of an out-dated dichotomy. Front Oncol. 2018;8:654. doi:10.3389/fonc.2018.00654

99. Cybulska P, Paula ADC, Tseng J, et al. Molecular profiling and molecular classification of endometrioid ovarian carcinomas. Gynecol Oncol. 2019;154(3):516-523. doi:10.1016/j.ygyno.2019.07.012

100. Mueller JJ, Schlappe BA, Kumar R, et al. Massively parallel sequencing analysis of mucinous ovarian carcinomas: genomic profiling and differential diagnoses. Gynecol Oncol. 2018;150 (1):127-135. doi:10.1016/j.ygyno.2018.05.008

101. Prat J, D'Angelo E, Espinosa I. Ovarian carcinomas: at least five different diseases with distinct histological features and molecular genetics. Hum Pathol. 2018;80:11-27. doi:10.1016/j.humpath.2018. 06.018

102. Imai A, Matsunami K, Takagi H, Ichigo S. Malignant neoplasia arising from ovarian remnants following bilateral salpingo-oophorectomy (Review). Oncol Lett. 2014;8(1):3-6. doi:10.3892/ol.2014.2089 
103. Lai CR, Yen MS, Wang PH. Neoplasms in the trocar site and peritoneal papillary serous cystadenocarcinoma. Taiwan J Obstet Gynecol. 2014;53(2):139-140. doi:10.1016/j.tjog.2014.04.002

104. Kho RM, Abrao MS. Ovarian remnant syndrome: etiology, diagnosis, treatment and impact of endometriosis. Curr Opin Obstet Gynecol. 2012;24(4):210-214. doi:10.1097/GCO.0b013e3283558539

105. Donnez O, Squifflet J, Marbaix E, Jadoul P, Donnez J. Primary ovarian adenocarcinoma developing in ovarian remnant tissue ten years after laparoscopic hysterectomy and bilatera salpingo-oophorectomy for endometriosis. J Minim Invasive Gynecol. 2007;14(6):752-757. doi:10.1016/j.jmig.2007.05.005

106. Bannay A, Chaignot $\mathrm{C}$, Blotière PO, et al. The best use of the Charlson comorbidity index with electronic health care database to predict mortality. Med Care. 2016;54(2):188-194. doi:10.1097/ MLR.0000000000000471

107. Pylväläinen J, Talala K, Murtola T, et al. Charlson comorbidity index based on hospital episode statistics performs adequately in predicting mortality, but its discriminative ability diminishes over time. Clin Epidemiol. 2019;11:923-932. doi:10.2147/CLEP.S218697

108. Schelde AB, Schmidt M, Madsen M, Nielsen SS, Frøkiær J, Christiansen CF. Impact of the Charlson Comorbidity Index score on risk prediction by single-photon emission computed tomography myocardial perfusion imaging following myocardial infarction. Clin Epidemiol. 2019;11:901-910. doi:10.2147/CLEP.S211555

109. Glassou EN, Kjørholt KK, Hansen TB, Pedersen AB. Delay in surgery, risk of hospital-treated infections and the prognostic impact of comorbidity in hip fracture patients. A Danish nationwide cohort study, 2005-2016. Clin Epidemiol. 2019;11:383-395. doi:10.2147/CLEP.S200454

110. Arostegui I, Gonzalez N, Fernández-de-Larrea N, et al., REDISSEC CARESS-CCR Group. Combining statistical techniques to predict postsurgical risk of 1-year mortality for patients with colon cancer. Clin Epidemiol. 2018;10:235-251. doi:10.2147/CLEP.S146729
111. Krassuski L, Vennedey V, Stock S, Kautz-Freimuth S. Effectiveness of decision aids for female BRCA1 and BRCA2 mutation carriers: a systematic review. BMC Med Inform Decis Mak. 2019;19(1):154. doi:10.1186/s12911-019-0872-2

112. Nené NR, Reisel D, Leimbach A, et al. Association between the cervicovaginal microbiome, BRCA1 mutation status, and risk of ovarian cancer: a case-control study. Lancet Oncol. 2019;20 (8):1171-1182. doi:10.1016/S1470-2045(19)30340-7

113. Huang T, Townsend MK, Wentzensen N, et al. Reproductive and hormonal factors and risk of ovarian cancer by tumor dominance: results from the Ovarian Cancer Cohort Consortium (OC3). Cancer Epidemiol Biomarkers Prev. 2019;2019:pii: cebp.0734. doi:10. 1158/1055-9965.EPI-19-0734

114. Trabert B, Michels KA, Anderson GL, et al. Circulating androgens and postmenopausal ovarian cancer risk in the Women's Health Initiative Observational Study. Int $J$ Cancer. 2019;145(8):20 51-2060. doi:10.1002/ijc.32157

115. Gasparri ML, Taghavi K, Fiacco E, et al. Risk-reducing bilateral salpingo-oophorectomy for BRCA mutation carriers and hormonal replacement therapy: if it should rain, better a drizzle than a storm. Medicina (Kaunas). 2019;55(8):415. doi:10.3390/medicina550 80415

116. Cheng M, Lee HH, Chang WH, et al. Weekly dose-dense paclitaxel and tri-weekly low dose cisplatin: A well-tolerated and effective chemotherapeutic regimen for first-line treatment of advanced ovarian, fallopian tube, and primary peritoneal cancer. Int J Environ Res Public Health. 2019;16(23):4794. doi:10.33 90/ijerph16234794
Clinical Epidemiology

\section{Publish your work in this journal}

Clinical Epidemiology is an international, peer-reviewed, open access, online journal focusing on disease and drug epidemiology, identification of risk factors and screening procedures to develop optimal preventative initiatives and programs. Specific topics include: diagnosis, prognosis, treatment, screening, prevention, risk factor modification,

\section{Dovepress}

systematic reviews, risk \& safety of medical interventions, epidemiology \& biostatistical methods, and evaluation of guidelines, translational medicine, health policies \& economic evaluations. The manuscript management system is completely online and includes a very quick and fair peer-review system, which is all easy to use. 